https://doi.org/10.15407/ujpe65.8.729

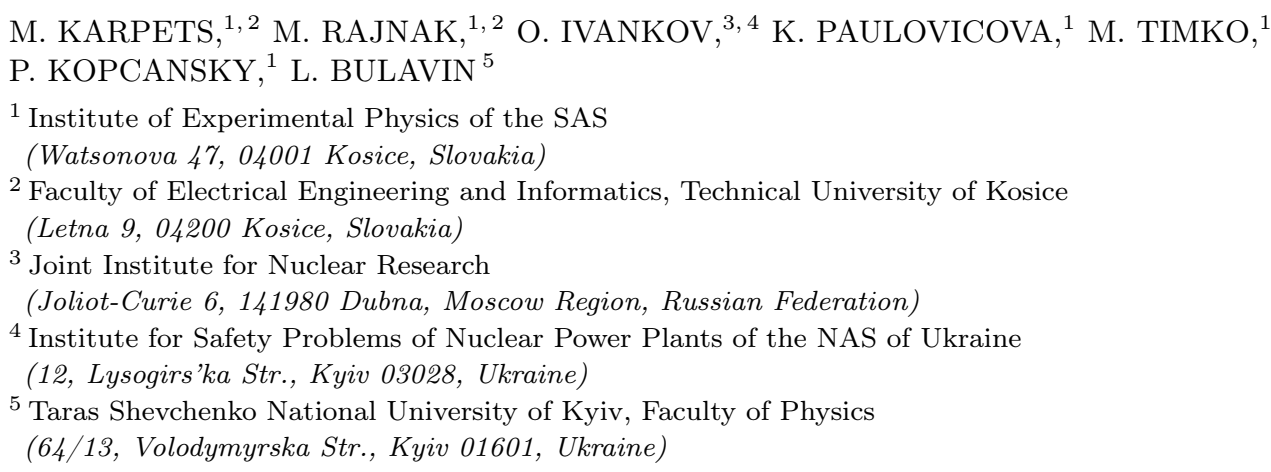

\title{
SMALL-ANGLE NEUTRON SCATTERING
} STUDY OF TRANSFORMER OIL-BASED FERROFLUIDS

\begin{abstract}
It is known that ferrofluids typically respond to magnetic fields and can be manipulated by such external fields. The particle assembly in magnetic nanofluids can be induced even by a direct current (dc) electric field. An experimental study of magnetic colloidal particles and their changes induced by an external electric field in a ferrofluid based on 2 transformer oils with different concentrations of nanoparticles is presented. By small-angle neutron scattering (SANS), we show the influence of the electric field intensity and the concentration on magnetic nanoparticle aggregates.
\end{abstract}

Keywords: external fields, magnetic fluids, magnetic nanoparticles, transformer oil-based ferrofluids.

\section{Introduction}

Magnetic nanoparticles (MNPs), as compared to bulk materials, possess quite distinct magnetic properties, and many attempts have been made to utilize their beneficial properties for technical and biomedical applications, e.g., for magnetic fluids, high-density magnetic recording, biomedical diagnosis and therapy, drug delivering.

Magnetic fluids (MFs) are liquid dispersions of magnetic nanoparticles (size $\sim 10 \mathrm{~nm}$ ) covered with surfactants that become strongly magnetized in the presence of a magnetic field [1]. Constituting unique properties, they studied intensively for diverse applications for the last 20 years. Magnetic fluids have been proven to provide benefits (thermal, dielectric, etc.) to power transformers. They can improve the cooling by increasing the fluid circulation within transformer windings due to the flow driven by a magnetic field. In addition, they can enhance the trans-

(C) M. KARPETS, M. RAJNAK, O. IVANKOV,

K. PAULOVICOVA, M. TIMKO, P. KOPCANSKY,

L. BULAVIN, 2020 former capacity to resist lightning impulses and minimize the effect of humidity in typical insulating fluids [2]. The advantages of magnetic fluids may be exploited to design smaller but more efficient new transformers or to prolong the life or loading capability of existing aggregates [3].

It is known that the electric polarization of MNPs increases the relative permittivity of ferrofluids [4]. However, the particle-particle interaction and their aggregation and polarization induced by electric fields have not been investigated enough. Recently, the studies with the dielectric spectroscopy method on thin layers of transformer oil-based ferrofluids (TOFF) showed that the external electric field induces the aggregation of MNPs [5]. In regard to the theory of converting free electrons to charged particles forming a streamer, such a response of MNPs to electric fields may influence the breakdown field strength of TOFF [6]. However, the breakdown voltage was found to increase not only due to the increasing voltage rise rate, but also due to the increasing nanoparticle concentration [7]. In [8], it was shown that the partial discharge inception voltage increases 


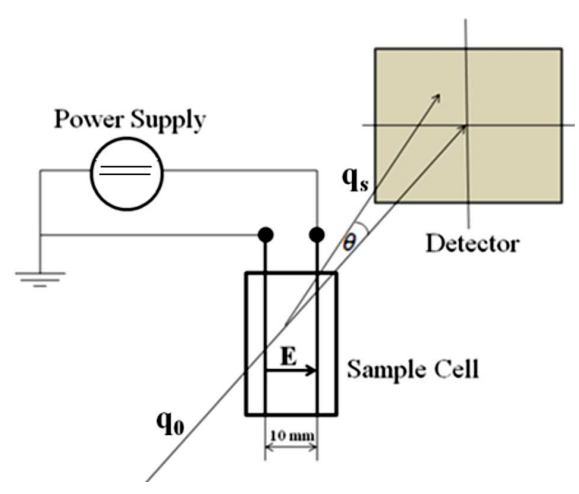

Fig. 1. Schematic representation of the cuvette for a sample with the electrical circuit and the neutron beam

quasilinearly with the concentration of superparamagnetic iron oxide nanoparticles, but the extinction voltage is practically unaffected.

Neutron diagnostics has a number of differences from X-ray and optical ones, which gives it considerable advantages in the study of nanomaterials. For neutrons, the main type of interaction with the matter is the nuclear interaction, and the amplitude of such interaction depends not only on the order number of the element in the Mendeleev table, but also on its isotope composition [9]. The neutron scattering methods are often applied to the research on biological materials. The influence of the magnetic content of magnetoferritin on the structure of the protein shell at low and moderate iron oxide loadings by the small-angle neutron scattering (SANS) was shown in [10]. The structure and interaction parameters of micelles in solutions of anionic surfactant sodium oleate in deuterated water were studied by SANS [11].

Neutron diagnostics is widely used for structural investigations of new materials for technical applications. Conducting SANS experiments with ferrofluids in dc electric fields, it was found that the anisotropic aggregates preferably orient in the direction of the applied electric field [12]. The effect of magnetic nanoparticle assembly formation at a planar interface between a transformer oil-based ferrofluid and singlecrystal silicon in non-homogeneous magnetic fields was studied by specular neutron reflectometry [13].

In this article, we present the experimental SANS study of a transformer oil-based ferrofluid with different concentrations of nanoparticles exposed to an external dc electric field. Based on the obtained results, we will discuss thethe probability of the formation of clusters in a TOFF and the influence of different parameters on SANS data.

\section{Materials and Methods}

The investigated MFs are based on a commercially available inhibited insulating transformer oils:

1) MOL TO 40A. Its basic physical properties provided by the manufacturer are as follows: density $0.867 \mathrm{~g} / \mathrm{cm}^{3}$, kinematic viscosity $22 \mathrm{~mm}^{2} / \mathrm{s}$, pour point $228 \mathrm{~K}$, flash point $413 \mathrm{~K}$, and interfacial tension $42 \mathrm{mN} / \mathrm{m}$. Three samples with magnetic volume fractions of $0.03 \%, 1.17 \%$, and $2.2 \%$ were studied. Their corresponding physical parameters are presented in Table;

2) SHELL Diala S4 ZX-I with such parameters: density $0.805 \mathrm{~g} / \mathrm{cm}^{3}\left(20{ }^{\circ} \mathrm{C}\right)$, kinematic viscosity $9.6 \mathrm{~mm}^{2} / \mathrm{s}$, pour point $233 \mathrm{~K}$ and flash point $464 \mathrm{~K}$. Samples with magnetic volume fractions of $0.03 \%$, $0.92 \%$, and $1.8 \%$ were studied.

The iron oxide nanoparticles were coprecipitated from the aqueous solution of $\mathrm{Fe}^{2+}$ and $\mathrm{Fe}^{3+}$ and stabilized by oleic acid in a well-proven way [14].

For the reported experiments, we used a standard quartz cuvette (Hellma, $1 \mathrm{~mm}$ thick) equipped with two stainless tubular electrodes inside, fixed $1 \mathrm{~cm}$ apart in the Teflon stoppers (Fig. 1). Our simulation confirmed a homogenous field in the middle of the cuvette, while the near-electrode regions exhibit a gradient field with the strongest intensity in the stoppers (Fig. 2). The numerical simulation of the field intensity inside the cuvette was simulated by the Finite Element Method Magnetics (FEMM 4.2) using a triangular element mesh and the iterative conjugate solver.

In situ, SANS experiments were carried out on the small-angle neutron diffractometer - time-of-flight YuMO instrument [15] at the pulsed IBR-2 reactor at JINR, Dubna, Russia. The experiments were performed at room temperature with a sample aperture of $8 \times 8 \mathrm{~mm}^{2}$ centered in the middle between the electrodes.

The general theory of the scattering of thermal neutrons shows that the differential scattering crosssection $d \Sigma / d \Omega$ can be considered with good approximation as a function of the momentum transfer, $\boldsymbol{q}$ :

$\frac{d \Sigma}{d \Omega}=\frac{1}{V} \sum_{k l} b_{k} b_{l}\left(e^{i \mathbf{q} \mathbf{r}_{k}}-e^{-i \mathbf{q r}_{l}}\right)$.

ISSN 2071-0194. Ukr. J. Phys. 2020. Vol. 65, No. 8 


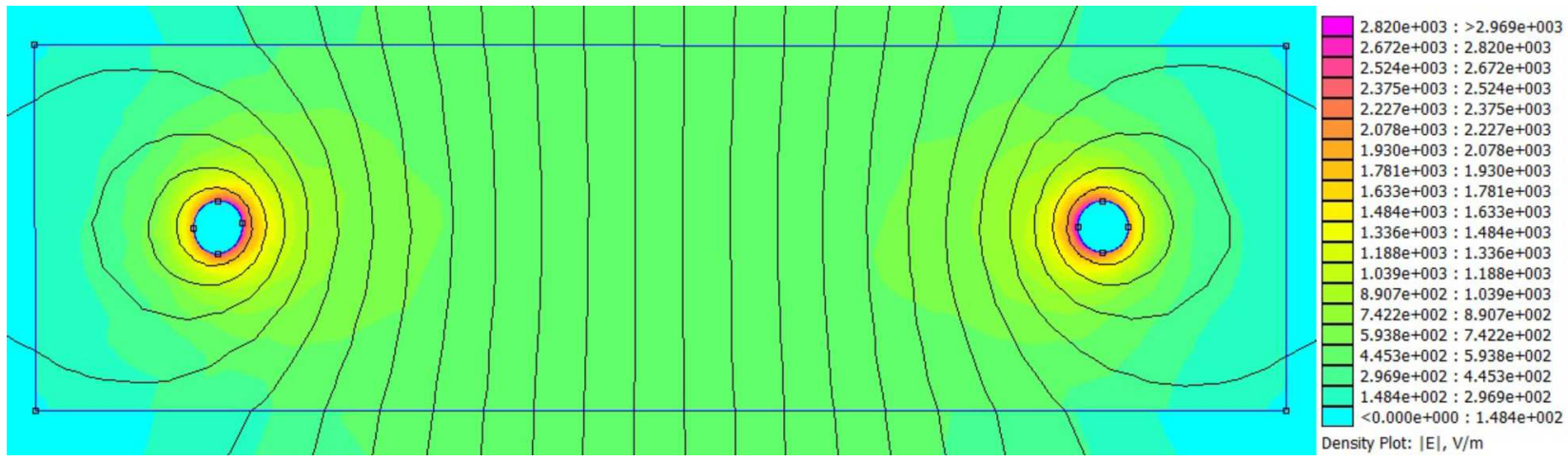

Fig. 2. Simulated equipotential field lines in the cross-section of the cuvette and electrodes with a potential difference of $6 \mathrm{kV}$

The basic physical parameters of the prepared magnetic nanofluid samples

\begin{tabular}{|c|c|c|c|c|c|c|}
\hline Samples & $\begin{array}{c}\text { Mass magnetization } \\
\text { of saturation, } \\
\mathrm{Am}^{2} / \mathrm{kg}\end{array}$ & $\begin{array}{c}\text { Volume magnetization } \\
\text { of saturation, } \\
\mathrm{kA} / \mathrm{m}\end{array}$ & $\begin{array}{c}\text { Magnetic } \\
\text { mass fraction, } \\
\%\end{array}$ & $\begin{array}{c}\text { Magnetic } \\
\text { volume fraction, } \\
\%\end{array}$ & $\begin{array}{l}\text { Density, } \\
\mathrm{g} / \mathrm{cm}^{3}\end{array}$ & $\begin{array}{c}\text { Magnetic } \\
\text { volume fraction }\end{array}$ \\
\hline MOL oil & - & - & - & - & 0.86 & - \\
\hline MF_MOL 0 & 0.17 & 0.14 & 0.18 & 0.03 & 0.863 & 0.005 \\
\hline MF_MOL 3 & 5.63 & 5.22 & 5.93 & 1.17 & 0.927 & 0.15 \\
\hline $\mathrm{MF}_{-}^{-} \mathrm{MOL} 5$ & 9.58 & 9.80 & 10.09 & 2.20 & 1.023 & 0.24 \\
\hline Diala oil & - & - & - & - & 0.807 & - \\
\hline MF_Shell 1 & 8.83 & 8.01 & 9.3 & 1.8 & 0.908 & 0.26 \\
\hline MF_Shell 2 & 4.8 & 4.13 & 5.1 & 0.92 & 0.86 & 0.13 \\
\hline MF_Shell 6 & 0.16 & 0.13 & 0.2 & 0.03 & 0.81 & 0.007 \\
\hline
\end{tabular}

In the small-angle neutron scattering experiment, we measured $d \Sigma / d \Omega$, the differential scattering as a function of $q$, the momentum transfer:

$q=\frac{4 \pi}{\lambda} \sin \frac{\theta}{2}$

where $\lambda$ is the neutron's wavelength, and $\theta$ is the scattering angle.

From relation (2), it can be seen that, to obtain the dependence $d \Sigma / d \Omega$, the scattering angle $\theta$, or the wavelength $\lambda$, or both parameters should be measured [16].

The main parameter of a material that defines the interaction with neutrons is the scattering length density (SLD)

$\rho=\frac{\rho_{m} N_{\mathrm{A}}}{M} \sum n_{i} b_{i}$,

where $b_{i}$ is an atomic incoherent scattering length, $M$ - atomic mass, $\rho_{m}$ material density, $N_{\mathrm{A}}-$ Avogadro's number.
The TOFF structure on the nanoscale under a dc electric field was followed by SANS representing the scattered neutron intensity $I$ as a function of the momentum transfer modulus $q$. Experimental measurements were performed with a cuvette fully filled with a ferrofluid. During the experiment, the sample was fixed, and only the intensity of the applied electric field was varied. Each curve was measured from 2 to 6 times.

For fitting the curves, we used the SasView software - a small-angle scattering analysis package for the analysis of $1 \mathrm{D}$ and $2 \mathrm{D}$ scattering data directly in the inverse space [17]. The Levenberg-Marquardt algorithm has been applied as the standard method for non-linear data fitting. As a gradient descent trust region method, it starts at the initial value of the function and steps in the direction of the derivative until it reaches the minimum. Set up as an explicit minimization of the sum of square differences between theory and model, it uses a numerical approximation of the Jacobian matrix to set the step direction 


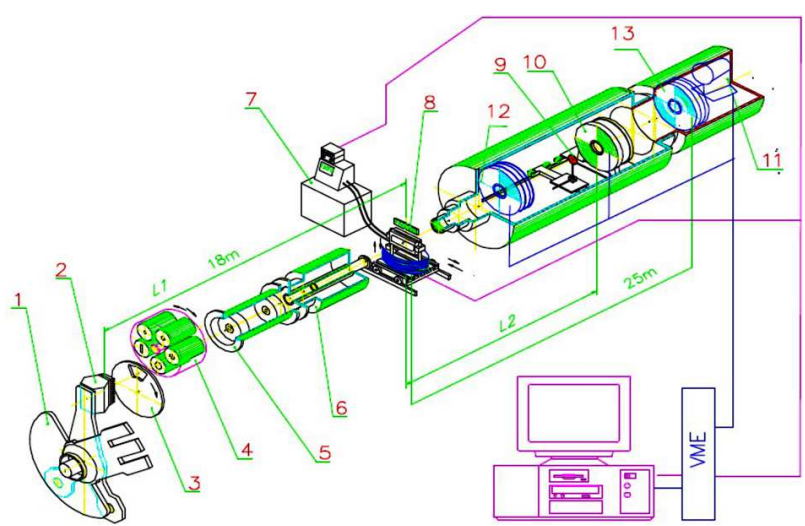

Fig. 3. YuMO SANS TOF diffractometer at the IBR-2 reactor [16]: 1) movable reflector; 2) moderator/cold moderator; 3) chopper (adapted to cold moderator); 4) first collimator; 5) vacuum tube; 6) second collimator; 7) liquid bath thermostat; 8) $\mathrm{V}$, graphite, $\mathrm{H}_{2} \mathrm{O}$ standards; 10 ) second circular detector (PSD) of thermal neutrons; 11) detector of the direct beam; 12) first circular detector of thermal neutrons; 13) third circular detector of thermal neutrons

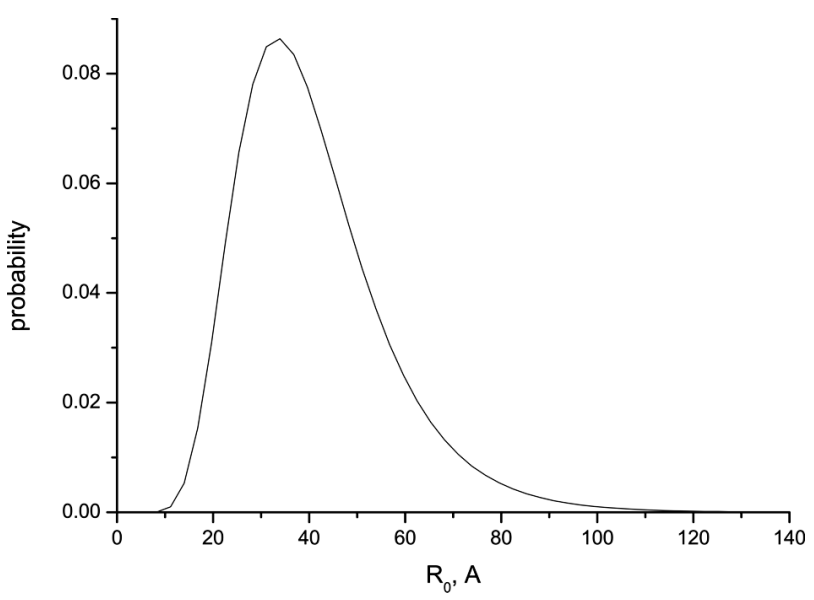

Fig. 4. Distribution of the radius of nanoparticles for the ferrofluids from SANS

and an adaptive algorithm to set the size of the trust region. During the fitting, we have used such parameters:

- Model - core-shell sphere;

- Resolution - 5\%;

- Polydispersity - lognormal;

- SLD of magnetite $-6.93 \times 10^{-6} \AA^{-2}$;

- SLD of oil and oleic acid $-0.08 \times 10^{-6} \AA^{-2}$.

All obtained experimental SANS data were processed with a theoretical model of core-shell particles. Core-shell type nanoparticles are a type of

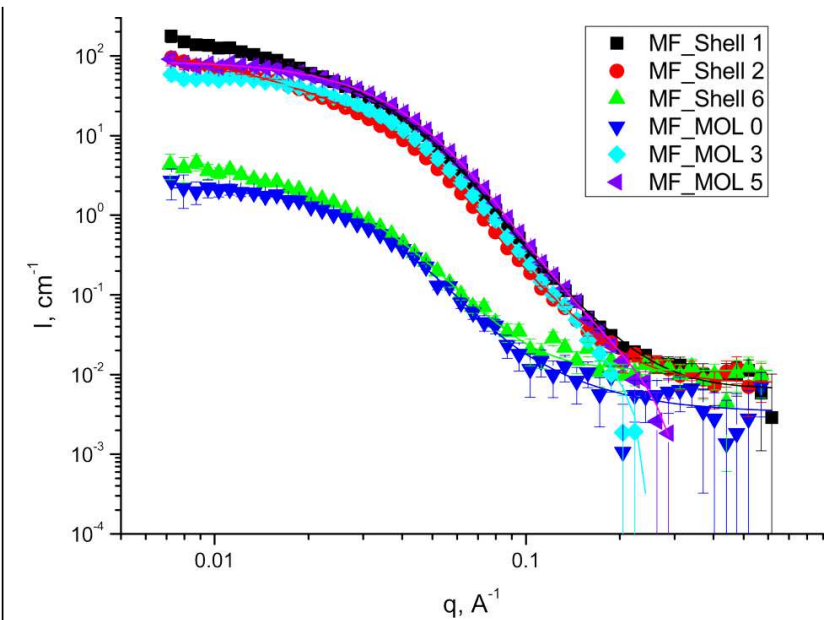

Fig. 5. SANS data (points) and the fit (curves) for the ferrofluids based on insulating transformer oils SHELL and MOL with electrodes without the dc electric field $(0 \mathrm{kV} / \mathrm{cm})$

biphasic materials which have an inner core structure and an outer shell made of different components (surfactant in the case of MNP). The mean radius of such particles was about $4 \mathrm{~nm}$ (Fig. 4). But the high scattering contrast between magnetite and a hydrogencontaining solvent allows one to neglect the scattering from the surfactant shell and the magnetic neutron scattering from MNPs according to [18].

The obtained experimental SANS dependences and fit for the ferrofluids based on insulating transformer oils SHELL and MOL with different concentrations of nanoparticles for voltage $0 \mathrm{kV}$ are plotted in Fig. 5. One can see a significant increase in the scattering intensity with the concentration of iron oxide nanoparticles. The cause for it is a higher quantity of scattering centers. The similar behavior is confirmed also in the presence of the electric field. The difference in SANS data for 2 types of insulating oil with comparable magnetic volume fractions of nanoparticles $(0.03 \%)$ in the electric field is presented in Fig. 6. It is seen that the scattering curve for SHELL oil is situated higher in the graph. It is because the SHELL oil has a lower density than MOL oil by about $6 \%$ and, according to (3), SLD lower by $6 \%$. The same situation is observed also for another particle concentration and in the presence of the dc electric field with strengths from $0 \mathrm{kV} / \mathrm{cm}$ (initial) to $4 \mathrm{kV} / \mathrm{cm}$.

Actually, there are almost no changes in SANS data with applying and increasing the dc electric field strengths for all samples. One can see the curves for

ISSN 2071-0194. Ukr. J. Phys. 2020. Vol. 65, No. 8 


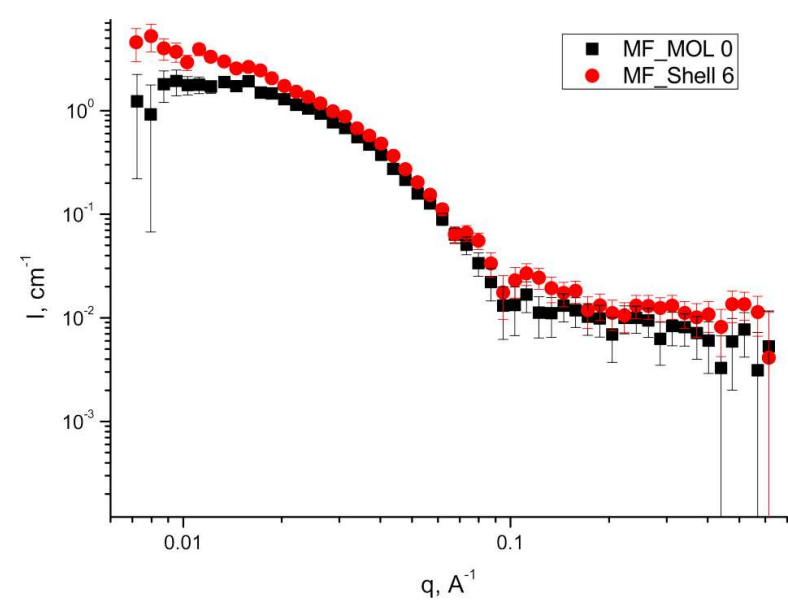

Fig. 6. SANS data for the ferrofluids based on insulating transformer oils SHELL and MOL with the magnetic volume fraction around $0.03 \%$ in a dc electric field of $6 \mathrm{kV} / \mathrm{cm}$

MF MOL 3 in Fig. 7. There is a little increase in the intensity for small $q$ for higher concentrations, but it is in the error range. We expected to get an obvious increase in $I_{0}$ with the voltage, as it was observed in [12]. If this was true, we would speculate that, with increasing the voltage, the nanoparticles migrate toward the electrodes (in the electric field gradient), and, as our beam was shining between the electrodes, we get scattering on a higher number of particles. Thus, the scattering curve obtained at higher voltages should represent two subsystems of scattering objects in the sample. The first one reflected in the intensity profile at $q>0.007 \AA^{-1}$, which we cover in the experiment reported in this paper, constitutes the non-aggregated particles. Another subsystem involves the particle aggregates, giving rise to the additional intense scattering signal at $q<0.007 \AA^{-1}$. Therefore, the expected aggregates are, probably, of greater size which is not possible to see in the $q$-range covered in the YuMO experiment. So, new measurements on instruments with wider $q$-range are required.

It is also useful to compare SANS results for a cuvette with MF without electrodes and with electrodes, but without the voltage (Fig. 8). Ideally, both curves should be equal. But, as the cuvette and the electrodes have finite size, slight differences appear, especially in the low $q$-range which is essential for us. The neutron beam (14 $\mathrm{mm}$ in diameter) catches the electrodes on the way through the sam-

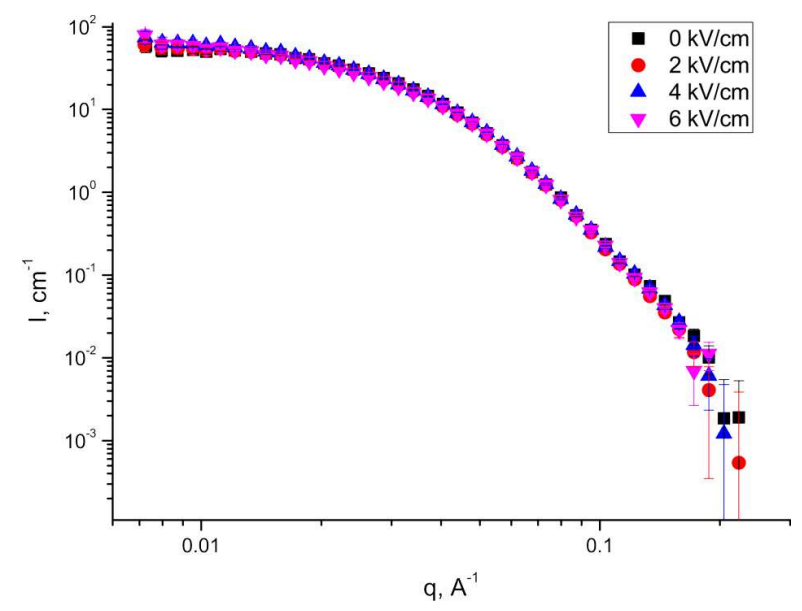

Fig. 7. SANS data for the MF_MOL 3 sample exposed to the dc electric field with strengths from $0 \mathrm{kV} / \mathrm{cm}$ (initial) to $6 \mathrm{kV} / \mathrm{cm}$

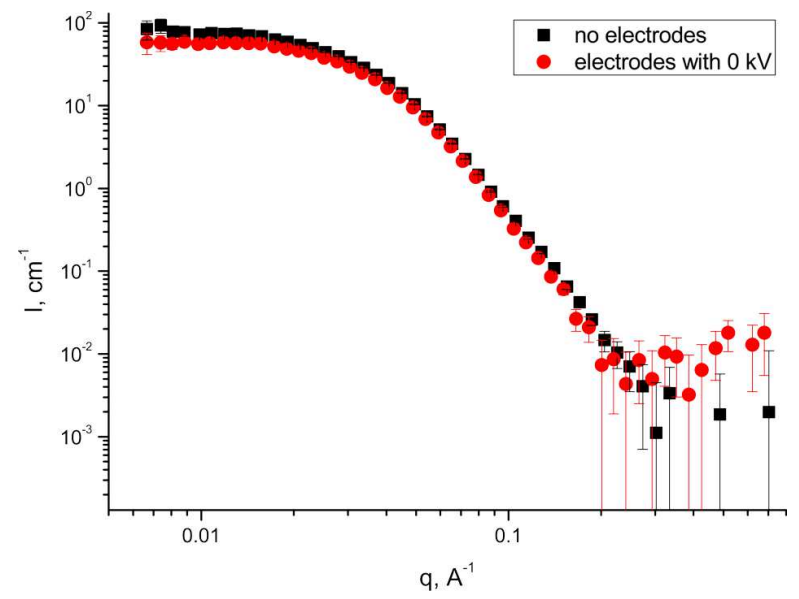

Fig. 8. SANS data for the MF_MOL 5 sample without electrodes and with electrodes without voltage

ple. As one single SANS measurement took $20 \mathrm{~min}$, we obtained the scattering intensities averaged in the time. Therefore, we miss the information about the quick particle assembly development driven by the applied field. One can use small-angle X-ray scattering (SAXS) with a point beam to avoid the effect of electrodes. By performing an SAXS experiment (for approximately 2 seconds), we will get the information about the quick particle assembly development driven by the applied field.

\section{Conclusions}

We have demonstrated the influence of the concentration of nanoparticles on SANS measurements of 
the classical magnetic fluids (magnetite coated with oleic acid in transformer oil). Changing the carrier liquid has a measurable effect on the scattering. It is shown that the neutron beam is quite sensitive to electrodes in such experimental setup. The qualitative and quantitative exploration of the ferrofluids based on insulating liquids under the action of external electric fields can shed light on some peculiar properties of ferrofluids (rheological, dielectric, electric breakdown) to boost and to support their effective application in the electrical engineering.

This work was supported by the Slovak Academy of Sciences and Ministry of Education in the framework of projects VEGA 2/0011/20, and Slovak Research and Development Agency under the Contract No. APVV-18-0160. The financial support in the frame of the JINR-Slovak Republic cooperation is acknowledged.

1. Colloidal Magnetic Fluids, edited by S. Odenbach (Springer, 2009).

2. J. Kudelcik, P. Bury, P. Kopcansky, M. Timko. Dielectric breakdown in mineral oil ITO 100 based magnetic fluid. Phys. Procedia 9, 78 (2010).

3. A. Skumiel, T. Hornowski, A. Jozefczak. Heating characteristics of transformer oil-based magnetic fluids of different magnetic particle concentrations. Int. J. Thermophys. 32, 876 (2011).

4. J. Miao, M. Dong, M. Ren, X. Wu, L. Shen, H. Wang. Effect of nanoparticle polarization on relative permittivity of transformer oil-based nanofluids. J. Appl. Phys. 113, 204103 (2013).

5. M. Rajnak, J. Kurimsky, B. Dolnik, P. Kopcansky, N. Tomasovicova, E. A. Taculescu-Moaca, M. Timko. Dielectric-spectroscopy approach to ferrofluid nanoparticle clustering induced by an external electric field. Phys. Rev. E 90, 032310 (2014).

6. J. G. Hwang, M. Zahn, L.A.A. Pettersson. Bipolar charging and discharging of a perfectly conducting sphere in a lossy medium stressed by a uniform electric field. J. Appl. Phys. 109, 084331 (2011).

7. P. Bartko, M. Rajnak, R. Cimbala, K. Paulovicova, M. Timko, P. Kopcansky, J. Kurimsky. Effect of electrical polarity on dielectric breakdown in a soft magnetic fluid. $J$. Magn. Magn. Mater. 497, 166007 (2020).

8. J. Kurimsky, M. Rajnak, R. Cimbala, J. Rajnic, M. Timko, P. Kopcansky. Effect of magnetic nanoparticles on partial discharges in transformer oil. J. Magn. Magn. Mater. 496, 165923 (2020).

9. M.L. Karpets, T.V. Tropin, L.A. Bulavin, J.W.P. Schmelzer. Neutron reflectometry for structural studies in thin films of polymer nanocomposites. Modeling. Nucl. Phys. At. Energy 19, 376 (2018) (in Ukrainian).
10. L. Melnikova, V.I. Petrenko, M.V. Avdeev, V.M. Garamus, L. Almasy, O.I. Ivankov, L.A. Bulavin, Z. Mitroova, P. Kopcansky. Effect of iron oxide loading on magnetoferritin structure in solution as revealed by SAXS and SANS. Colloids Surf. B 123, 82 (2014).

11. V.I. Petrenko, M.V. Avdeev, V.M. Garamus, L.A. Bulavin, P. Kopcansky. Impact of polyethylene glycol on aqueous micellar solutions of sodium oleate studied by small-angle neutron scattering. Colloids Surf. A 480, 191 (2015).

12. M. Rajnak, V.I. Petrenko, M.V. Avdeev, O.I. Ivankov, A. Feoktystov, B. Dolnik, J. Kurimsky, P. Kopcansky, M. Timko. Direct observation of electric field induced pattern formation and particle aggregation in ferrofluids. Appl. Phys. Lett. 107, 073108 (2015).

13. A. Nagornyi, V.I. Petrenko, M. Rajnak, I.V. Gapon, M.V. Avdeev, B. Dolnik, L.A. Bulavin, P. Kopcansky, M. Timko. Particle assembling induced by non-homogeneous magnetic field at transformer oil-based ferrofluid/silicon crystal interface by neutron reflectometry. Appl. Surf. Sci. 473, 912 (2019).

14. L. Vekas, M.V. Avdeev, D. Bica. NanoScience in Biomedicine, edited by D. Shi (Springer, 2009).

15. I. Kuklin, A.Kh. Islamov, V.I. Gordeliy. Scientific reviews: two-detector system for small-angle neutron scattering instrument. Neutron News 16, 16 (2005).

16. M. Balasoiu, M.V. Avdeev, V. Aksenov, V. Ghenescu, M. Ghenescu, G. Torok, L. Rosta, D. Bica, L. Vekas, D. Hasegan. Structural studies of ferrofluids by small angle neutron scattering. Rom. Repts. Phys. 56, 601 (2004).

17. http://www.sasview.org/

18. M.V. Avdeev, D. Bica, L. Vekas, V.L. Aksenov, A.V. Feoktystov, O. Marinica, L. Rosta, V.M. Garamus, R. Willumeit. Comparative structure analysis of non-polar organic ferrofluids stabilized by saturated mono-carboxylic acids. J. Colloid Interface Sci. 334, 37 (2009).

Received 13.05.20

M. Карпецъ, М. Райняк,

О. Іванъков, К. Павловічова, М. Тімко,

П. Копчансъкий, Л. Булавін

ВИВЧЕННЯ МАГНІТНИХ РІДИН НА ОСНОВІ

ТРАНСФОРМАТОРНИХ МАСТИЛ МЕТОДОМ

МАЛОКУТОВОГО РОЗСІЯННЯ НЕЙТРОНІВ

$\mathrm{P}$ е $з$ ю м е

Відомо, що магнітні рідини зазвичай реагують на магнітні поля, і ними можна маніпулювати такими зовнішніми полями. Агрегація частинок у магнітних нанорідинах може бути викликана навіть постійним електричним полем. Представлено експериментальне вивчення магнітних колоїдних частинок і їх зміни під впливом зовнішнього електричного поля в магнітних рідинах на основі двох трансформаторних мастил з різними концентраціями наночастинок. За допомогою методу малокутового розсіяння нейтронів показано вплив інтенсивності електричного поля і концентрації магнітних наночастинок на їх агрегацію.

ISSN 2071-0194. Ukr. J. Phys. 2020. Vol. 65, No. 8 